\title{
Prescribing in Pregnancy
}

\section{Anticoagulants}

\author{
M DE SWIET
}

The main indications for the use of anticoagulants in pregnancy are the treatment and prevention of deep vein thrombosis and pulmonary embolus and the anticoagulation treatment of patients with artificial heart valves. The increased risk of thromboembolism and the vulnerability of the fetus to oral anticoagulants make management of anticoagulant treatment in pregnancy particularly difficult.

\section{Safety of anticoagulants during pregnancy}

\section{HEPARIN}

There is no evidence that heparin is teratogenic; it does not cross the placenta. A retrospective review of published work suggested that the incidence of fetal loss may be as high with heparin as with warfarin (see below), ${ }^{1}$ but this has not been confirmed in a small clinical trial. ${ }^{2}$ There may, however, be a slightly increased risk of premature labour. ${ }^{2}$ Heparin is probably not secreted in breast milk, but, even if it were, it would be inactivated in the infant's stomach.

The main problems associated with heparin are bleeding and bone demineralisation in the mother. Bleeding usually occurs because of excess heparin administration, which is rare in patients taking subcutaneous heparin in doses up to 20000 units a day in pregnancy or 16000 units a day after delivery. Since heparin is excreted by the kidney, patients who have renal insufficiency or preeclampsia are at extra risk. Patients should not bleed because of excess heparin administration, even at delivery or during surgical procedures, if the heparin assay is less than 0.4 units $/ \mathrm{ml} .^{3}$ More intensive intravenous heparin treatment, such as that used in the first phase of treatment of deep vein thrombosis, is associated with a high risk of bleeding, particularly if the heparin is given intermittently rather than by continuous infusion. If the protamine sulphate neutralisation test shows a concentration of heparin greater than $1 \mathrm{unit} / \mathrm{ml}$ there is a definite risk of spontaneous bleeding. ${ }^{4}$ Patients may also bleed because of thrombocytopenia induced by heparin treatment. ${ }^{5.7}$ This is an uncommon idiosyncratic reaction related to the formation of platelet antibodies.

Maternal bone demineralisation was also considered an idiosyncratic reaction as a few patients taking 10000 units of heparin a day or more for at least three months have suffered crushed vertebrae and rib fractures. ${ }^{8-10}$ It appears, however, that subclinical bone demineralisation may occur in a large proportion of women taking heparin for three months or more. ${ }^{11}$ The mechanism is unknown, although reduced concentrations of 1,25-dihydroxy vitamin $\mathrm{D}$ have been implicated. ${ }^{12}$

Queen Charlotte's Maternity Hospital and Brompton Hospital, London, and Department of Clinical Pharmacology, Faculty of Medicine, University College, London

M DE SWIET, MD, FRCP, consultant physician and senior lecturer

This series is edited by Dr P C Rubin.

\section{WARFARIN}

Warfarin is teratogenic. It causes abnormalities of cartilage and bones, chondrodysplasia punctata, ${ }^{13}$ and, rarely, the asplenia syndrome.${ }^{14}$ Although these are definite risks, the incidence of such abnormalities is probably less than $5 \%$ in women taking warfarin in the first trimester. For example, none occurred in 22 pregnancies during which women with artificial heart valves took warfarin in the first trimester. ${ }^{15}$ There is also a high abortion rate associated with warfarin, ${ }^{15}$ but it is not clear to what extent the condition for which the warfarin is being used contributes to this risk. ${ }^{16}$ In addition, warfarin has been associated with abnormalities of the central nervous system such as microcephaly, optic atrophy, cranial nerve palsies, and hydrocephalus. ${ }^{17}$ These abnormalities are not specific to treatment at any particular stage of the pregnancy. Since warfarin crosses the placenta freely, it has been suggested that they are due to repeated small episodes of intracerebral haemorrhage. Such haemorrhage is even more likely to occur at the end of pregnancy and during labour, when frank intracerebral and retroplacental haemorrhages have been reported. ${ }^{18}$ Warfarin is not secreted in breast milk in appreciable amounts. ${ }^{19}$

The risk of bleeding in the mother is not specific to pregnancy, but women may bleed for other reasons in pregnancy, and warfarin certainly exacerbates this risk. Secondary postpartum haemorrhage and wound haematomas are major risks in women taking warfarin in the first 10 days after delivery. ${ }^{20}$

\section{PHENINDIONE}

It has been claimed that some of the adverse fetal effects associated with warfarin are less common in patients taking phenindione, but there is inadequate clinical experience to confirm this. ${ }^{21}$ In contrast to warfarin phenindione is excreted in breast milk, and this has caused bleeding in the neonate..$^{22}$

\section{THROMBOLYTIC TREATMENT}

Streptokinase and urokinase have both been used in pregnancy,,$^{23}$ but they have not been studied recently. Such drugs may cause bleeding, premature labour, ${ }^{24}$ and incoordinate uterine action, which may be due to release of fibrin degradation products. ${ }^{25}$

\section{Effect of pregnancy on clinical efficacy of anticoagulants}

\section{HEPARIN}

Because the concentrations of clotting factors increase in pregnancy higher doses of heparin - that is, 10000 units 12 hourly - are prescribed for subcutaneous prophylactic treatment. It is not known exactly when concentrations of these clotting factors return to normal after delivery, but blood volume also decreases after 
delivery and therefore the dose of heparin is usually decreased to 8000 units 12 hourly or 5000 units eight hourly.

\section{WARFARIN}

Warfarin requirements probably do not change during pregnancy. In the few cases in which warfarin is prescribed in pregnancy, however, there will be concern about its effects on the fetus. These may be dose related, so warfarin dosage is usually adjusted to maintain a prothrombin ratio at the lower, rather than the higher, end of the therapeutic range $(1 \cdot 8-4)$.

\section{Clinical use of anticoagulants during pregnancy}

\section{PULMONARY EMBOLUS AND DEEP VEIN THROMBOSIS}

Because of the unreliability of clinical diagnosis and the risks of anticoagulant treatment every effort should be made to make the diagnosis of pulmonary embolus objectively, even in pregnancy. ${ }^{26}$ Patients with pulmonary embolus who remain shocked one hour after the initial episode should be treated by pulmonary embolectomy. If this is not available thrombolytic treatment should be considered. The place of surgical treatment in the management of massive iliofemoral thrombosis is unclear. All other patients should be treated with anticoagulants.

Initial treatment should be with intravenous heparin given by continuous infusion, starting at a dose of 40000 units a day (1600 units an hour). Patients with large thromboses may require higher infusion rates. Although the partial thromboplastin time is often used for control of heparin treatment, we have found that the protamine sulphate neutralisation test is more helpful clinically: ${ }^{4}$ This test measures the concentration of heparin in the blood, which should be 0.6 to 1.0 units $/ \mathrm{ml}$. After an arbitrary period of five to ten days, subcutaneous heparin should be substituted. Warfarin should not be used in these cases because of the risks to the fetus. The initial dose of subcutaneous heparin is 10000 units 12 hourly. This a low dose which does not affect the whole blood clotting time or the partial thromboplastin time. The dose is controlled by the heparin assay, ${ }^{27}$ which should be less than 0.4 units $/ \mathrm{ml}$. The heparin assay should be repeated as often as the patient would normally attend the clinic for antenatal care. Patients can give themselves the heparin and may be discharged from hospital. The only inconveniences are pain at the injection site and bruising. Because of the continuing risk of recurrent thromboembolism subcutaneous heparin treatment should be continued for the remainder of pregnancy and through labour, provided that the heparin assay is less than $0.4 \mathrm{units} / \mathrm{ml}$. Epidural anaesthesia should not be given because of the small risk of epidural haematoma. ${ }^{28}$

After delivery the dose of heparin must be reduced to 8000 units 12 hourly. The length of time after delivery that anticoagulants should be continued is unknown; six weeks is generally recommended. ${ }^{29}$ One week after delivery, when the risk of secondary postpartum haemorrhage has diminished, treatment may be changed to warfarin if the patient prefers oral treatment. Since warfarin treatment necessitates frequent prothrombin estimation warfarin is initially not much less inconvenient than heparin for the patient. As stated above, breast feeding is safe for women taking heparin or warfarin ${ }^{19}$ but not phenindione.

\section{PROPHYLAXIS AGAINST VENOUS THROMBOEMBOLISM}

What prophylaxis, if any, should be used in a pregnant woman who has had deep vein thrombosis or a pulmonary embolus in the past? The risk of recurrence in pregnancy appears to be $5 \%^{30}$ to $13 \%^{31}$ irrespective of the circumstances of the previous episode of thromboembolism and its nature. Drugs which have been shown by clinical trial to reduce the risk of thromboembolism associated with surgery (not in pregnancy) include dextran, warfarin, and heparin. It is clearly impractical to use dextran throughout pregnancy, and warfarin should not be used for routine prophylaxis for the reasons indicated above.

The question remains whether subcutaneous heparin should be used throughout pregnancy. In a patient who has had a single episode of thromboembolism heparin should probably not be used because of the risks of heparin treatment indicated above and, in particular, because of the risk of bone demineralisation, which has occurred in patients taking as little as 10000 units of heparin a day. ${ }^{10}$ If this form of bone demineralisation is similar to osteoporosis it will be resistant to treatment and exacerbated by the menopause. Treatment with lower doses of heparin (less than 10000 units a day), other heparinoids, ${ }^{32}$ or heparin with vitamin $\mathrm{D}$ and calcium supplementation may obviate the risks of conventional prophylactic heparin treatment and also be effective. Until these suggestions have been tested by clinical trial, however, prophylactic heparin treatment is not justified in the antenatal period in patients who have had a single episode of thromboembolism in the past.

Our policy with such patients is to counsel them about the varied clinical presentation of thromboembolism in the antenatal period and to urge them to attend hospital if they have any warning symptoms; to use no specific prophylaxis in the antenatal period; and to give them 1 litre of dextran 70 over about six hours in labour, thus permitting epidural anaesthesia. After delivery these patients should be treated with subcutaneous heparin 8000 units every 12 hours for at least one week. This may be changed to warfarin after one week if the patient wishes, but a total of six weeks' treatment should be given after delivery as described above. The major risks with this policy are thromboembolism in the antenatal period and anaphylaxis caused by dextran. We reported one possible antenatal pulmonary embolism in 26 patients treated in this way ${ }^{30}$ and have subsequently managed another 20 patients without further thromboembolism. Anaphylaxis should not be a problem provided the first part of the dextran infusion is given slowly. Since dextran may interfere with blood group cross matching, blood samples must be taken for cross matching before giving dextran.

Patients who have the rare antithrombin III, protein C, or protein $S$ deficiencies require special management in pregnancy. ${ }^{33}$ Other patients who have had more than one episode of thromboembolism but in whom no predisposing cause can be found should be warned before pregnancy that they are probably at increased risk and offered heparin prophylaxis throughout pregnancy. Patients with lupus anticoagulant are paradoxically also at risk of developing thromboembolism, ${ }^{34}$ which may be arterial. It is not clear to what extent treatment with prednisone or aspirin, which have been advocated for the management of this condition in pregnancy, ${ }^{3+35}$ reduce this risk. Our practice has been to offer such patients intrapartum and postnatal prophylaxis as described above if they have a history of thromboembolism but to withhold prophylaxis if they have no such history.

\section{PATIENTS WITH ARTIFICIAL HEART VALVES}

Patients with artificial heart valves are usually treated with warfarin. In pregnancy, because of the problems associated with warfarin treatment, attempts have been made to substitute subcutaneous heparin. This is unacceptable, however, because of the catastrophic risks of peripheral arterial embolisation or thrombosis of the valve in situ. ${ }^{15} 36$ Possible alternative treatments such as subcutaneous heparin and dipyridamole ${ }^{38}$ high dose subcutaneous heparin,,$^{39}$ or long term intravenous heparin ${ }^{\text {t0 }}$ need to be assessed by clinical trial. Until there is adequate satisfactory experience of these alternative treatments such patients should continue to take warfarin in pregnancy despite the risks to both fetus and mother. The patient should be warned about these risks before pregnancy and ideally before the original operation. These risks may, however, have been exaggerated. ${ }^{41}$ So far as pregnancy is concerned, there is no doubt that tissue valves, which do not need anticoagulation, are superior to artificial valves. ${ }^{42}$ Unfortunately, they do not last so long. ${ }^{43}$

Although warfarin is generally recommended for the management of these patients in pregnancy, ${ }^{44}$ the risk of fetal and maternal 
bleeding becomes too great at the end of pregnancy and during delivery. At about 36 weeks' gestation high dose intravenous heparin should be substituted for warfarin and given by continuous infusion to maintain a heparin concentration of 0.6 to 1.0 units $/ \mathrm{ml}$. About two weeks' later, by which time the anticoagulant effects of warfarin on the fetus should have worn off, and if the situation is obstetrically favourable, the patient should be delivered. This can be achieved safely by stopping heparin treatment and delivering the patient 6-12 hours later, when the thrombin time has been shown to be normal. After delivery high dose intravenous heparin should be restarted, and this should be changed to warfarin about one week later.

\section{Conclusion}

Anticoagulant treatment should not be undertaken lightly in pregnancy. It poses additional risks to both the mother and the fetus. Further clinical trials are necessary to determine the best ways to manage prophylaxis for patients who have had thromboembolism in the past and also for those with artificial heart valves.

\section{References}

1. Hall JG, Pauli RM, Wilson KM. Maternal and fetal sequelae of anticoagulation during pregnancy.

Am f Med 1980;68:122-40.
2 Howell R, Fidler J, Letsky E, de Swiet M. The risks of antenatal subcutaneous heparin Howell R, Fidler J, Letsky E, de Swiet M. The risks of antena
prophylaxis: a controlled trial. Br J Obstet Gynaecol 1983;90:1124-8.

3 Bonnar J. Thromboembolism in obstetric and gynaecological patients. In: Nicolaides AN, ed. Thromboembolism aetiology, advances in prevention and management. Lancaster: MTP Press, 1975:311-34.

4 Dacie J. Practical haematology. Edinburgh: Churchill Livingstone, 1975:413-4.

5 Cines DB, Kaywin P, Bina M, Tomaski A, Schreiber AD. Heparin-associated thrombocytopenia. N Engl f Med 1980;303:788-95.

6 Chong BH, Pitney WR, Castaldi PA. Heparin-induced thrombocytopenia: association of thrombotic complications with heparin-dependent IgG antibody that induces thromboxane synthesis and platelet aggregation. Lancet 1982;ii:1246-8.

7 Hatij CG. Heparin-induced thrombocytopenia in pregnancy. $\mathcal{F}$ Repro Med 1984;29:337-8.

8 Griffith GC, Nichols G, Asher JD, Hanagan B. Heparin osteoporosis. JAMA 1965;193:91-4.

9 Avioli LV. Heparin-induced osteopenia: an appraisal. Adv Exp Med Biol 1975;52:375-87.

9 Avioli LV. Heparin-induced osteopenia: an appraisal. Adv Exp Med Biol 1975;52:375-87.
10 Griffiths HT, Liu DTY. Severe heparin osteoporosis in pregnancy. Postgrad Med J 1984;60: Griffiths

11 de Swiet $M$, Dorrington Ward P, Fidler J, et al. Prolonged heparin therapy in pregnancy causes bone demineralisation (heparin induced-osteopenia). Br f Obstet Gynaecol 1983;90:1129-34.

12 Aarskog D, Lage A, Markestad T, Ulstein M, Sagen N. Heparin-induced inhibition of 1 , 25-dihydroxyvitamin D formation. Am $\mathcal{F}$ Obstet Gymecol 1984;148:1141-2.
13 Stevenson RE, Burton M, Ferlauto GJ, Taylor HA. Hazards of oral anticoagulants during pregnancy. FAMA 1980;243:1549-51.

14 Cox DR, Martin L, Hall BD. Asplenia syndrome after fetal exposure to warfarin. Lancet 1977;ii:1134.

15 Chen WWC, Chan CS, Lee PK, Wang RYC, Wong VCW. Pregnancy in patients with prosthetic heart valves: an experience with 45 pregnancies. $Q \mathcal{J}$ Med 1982;51:358-65.

16 Javares T, Coto EC, Maiques V, Rincon A, Such M, Caffarena JM. Pregnancy after heart valve replacement. Int $\mathcal{f}$ Cardiol 1984;5:731-9.

17 Holzgreve W, Carey JC, Hall BD. Warfarin-induces fetal abnormalities. Lancet 1976;ii:914-5. 18 Villasanta U. Thromboembolic disease in pregnancy. Am $\mathcal{F}$ Obstet Gynecol 1965;93:142-60.

19 Orme M L'E, Lewis PJ, de Swiet M, et al. May mothers given warfarin breast-feed their infants? BrMed f 1977;i:1564-5.

20 de Swiet $M$, Letsky E, Mellows $\mathbf{H}$. Drug treatment and prophylaxus of thromboembolism in pregnancy. In: Lewis PJ, ed. Therapeutic problems in pregnancy. Lancaster: MTP Press, pregnancy.

21 Oakley CM, Hawkins DF. Pregnancy in patients with prosthetic heart valves. $\mathrm{Br} M e d f$ 1983;287:358.

22 Eckstein H, Jack B. Breast feeding and anticoagulant therapy. Lancet 1970;i:672-3.

23 Pfeifer GW. The use of thrombolytic therapy in obstetrics and gynaecology. Australian Annals of Medicine 1970;suppl:28-31.

24 Amias AG. Streptokinase, cerebral vascular disease-and triplets. Br Med f 1977;i:1414-5.

25 Hall RJC, Young C, Sutton GC, Cambell S. Treatment of acute massive pulmonary embolism by streptokinase during labour and delivery. $B r$ Med $\mathcal{F}$ 1972;iv:647-9.

26 de Swiet M. Thromboembolism. In: de Swiet M, ed. Medical disorders in obstetric practice. Oxford: Blackwell Scientific Publications, 1984:95-115.

27 Denson KWE, Bonnar J. The measurement of heparin: a method based on the potentiation of anti-factor Xa. Thrombosis et Diathesis Haemorrhagica 1973;30:471.

28 Crawford JS. Principles and practice of obstetric anaesthesia. 4th ed. Oxford: Blackwell Scientific Publications, 1978:182-3.

29 de Swiet M, Bulpitt CJ, Lewis PJ. How obstetricians use anticoagulants in the prophylaxis of thromboembolism. Journal of Obstetrics and Gynaecology, 1980;1:29-32.

30 Lao TT, de Swiet M, Letsky E, Walters BNJ. Prophylaxis of thromboembolism in pregnancy: an alternative. Br $\mathcal{F}$ Obstet Gynaecol 1985;92:202-6.

31 Badaracco MA, Vessey $M$. Recurrence of venous thromboembolism disease and use of oral contraceptives. Br Med J 1974;i:215-7.

32 Harenberg J, Zimmerman R, Schwarz F, Kübler W. Treatment of heparin-induced thrombocytopenia with thrombosis by new heparinoid. Lancet 1983;i:986-7.

33 de Swiet M. Thromboembolism. Clin Haematol 1985;14:643-60.

34 Lubbé WF, Butler WS, Palmer SJ, Liggins GC. Lupus anticoagulant in pregnancy. Br $\mathcal{f}$ Obstet Gynaecol 1984;91:357-63.

35 Ware Branch D, Scott JR, Kochenour NK, Hershgold E. Obstetric complications associated with the lupus anticoagulant. $N$ Engl f Med 1985;313:1322-6.

36 Bennett GG, Oakley CM. Pregnancy in a patient with a mitral valve prosthesis. Lancet 1968; : 616-9.

37 Wang RYC, Lee PK, Chow JSF, Chen WWC. Efficacy of low-dose, subcutaneously administered heparin in treatment of pregnant women with artificial heart valves. Med f Aust 1983;2:126-8.

38 Biale $\mathrm{Y}$, Cantor $\mathrm{A}$, Lewen Thal $\mathrm{H}$, Gueron $M$. The course of pregnancy in patients with artificial heart valves treated with dipyridamole. International foumal of Obstetrics and Gynaecology 1980;18:128-32.

39 Rabinovici J, Mani A, Barkai G, Hod H, Frenkel Y, Mashiach S. Long term ambulatory anticoagulation by constant subcutaneous heparin infusion in pregnancy. Br $\mathrm{f} \mathrm{Obstet} \mathrm{Gynaecol}$ (in press).

40 Nelson DM, Stempel LE, Fabri PJ, Talbert M. Hickman catheter use in a pregnant patient requiring therapeutic heparin anticoagulation. Am 7 Obstet Gynecol 1984;149:461-2.

41 Chong MKB, Harvey D, de Swiet $M$. Follow up study of children whose mothers were treated with warfarin during pregnancy. Br $\mathcal{F}$ Obstet Gynaecol 1984;91:1070-3.

42. Beadle EM, Luepker RV, Williams PP. Pregnancy in a patient with procine valve xenografts. Am Heart I 1979;98:510-2.

43 Kirklin JW. The replacement of cardiac valves. $N$ Engl F Med 1981;304:291-2.

44 Oakley CM. Pregnancy in patients with prosthetic heart valves. Br Med $\mathcal{F} 1983 ; 286: 1680-2$.
I have been advised that it is now considered negligent not to inject all newborn babies with vitamin $K$ in an effort to prevent haemorrhagic disease and that there are no harmful effects. How can we be so sure that vitamin $K$ is harmless when injected?

Vitamin $\mathrm{K}$ has been given in a dose of $1 \mathrm{mg}$ in various forms to neonates since the 1940s in an effort to prevent haemorrhagic disease of the newborn. The incidence of this disease is now low but this does not necessarily mean that vitamin $\mathrm{K}$ is effective but more probably reflects on fewer asphyxiated or small for dates babies with better neonatal resuscitation. If haemorrhagic disease of the newborn is related to hypoprothrombinaemia and intramuscular vitamin $\mathrm{K}$ improves the prothrombin time it seems sensible to give it to those babies at risk. What is worrying are reports of haemorrhagic disease of the newborn in healthy breast fed babies who have not received vitamin $\mathrm{K} .{ }^{1}$ It is therefore tempting to give oral vitamin $\mathrm{K}$ to those babies not at great risk on the grounds that most of them will achieve vitamin $K$ concentrations above those of normal adults but acknowledging that the oral route is unreliable. Others would argue that if intramuscular vitamin $\mathbf{K}$ always achieves good concentrations this should be the chosen route for all babies. Most people would opt for the compromise solution. We do not know the long term consequences of high concentrations of vitamin $\mathbf{K}$ immediately after birth. Kernicterus was linked with excessive doses of menadiol sodium diphosphate (Synkavit) but so far as is known that is the only long term problem reported. It is somewhat of a philosophical decision balancing the possible mistakes made by the routine injection of vitamin $\mathrm{K}$ to all newborn babies against the odd case of haemorrhagic disease of the newborn still occurring when adequate blood concentrations have not been achieved by the oral route. The decision must be taken locally depending on the practicalities.-J G BISSENDEN, consultant paediatrician, Birmingham.

1 McNinch AW, Upton C, Samuels M, et al. Plasma concentrations after oral or intramuscular vitamin $\mathrm{K}$ in neonates. Arch Dis Child 1985;60:814-8.

\section{Is saccharin known to have any carcinogenic effect in man?}

No. There have been at least a dozen attempts by epidemiologists to throw light on this question, specifically in relation to the risk of cancer of the urinary bladder, which is the only target for carcinogenicity by saccharin in the rat. Overall the results of the investigations do not suggest that consumption of saccharin is associated with an increased risk of bladder cancer in man. It is always arguable, however, that available epidemiological methods are not sensitive enough to detect small risks. Also, it is theoretically possible that a tissue other than the bladder is a target for saccharin carcinogenicity in man. This latter argument carries any real force only in the case of genotoxic carcinogens. At present it seems probable that the production of bladder tumours by saccharin in the rat is dependent on a non-genotoxic mechanism which operates only under conditions of excessively high exposure. If so then there is no basis for expecting man to be at any risk. The present consensus view, therefore, is that priority should be given to elucidating the mechanisms by which saccharin causes bladder carcinogenesis in rats and not on further epidemiological studies in man.FRANCIS J C ROE, independent consultant in toxicology and cancer research, London. 